\title{
Front Matter: Volume 6887
}

, "Front Matter: Volume 6887," Proc. SPIE 6887, MOEMS and Miniaturized Systems VII, 688701 (22 February 2008); doi: 10.1117/12.791932

SPIE Event: MOEMS-MEMS 2008 Micro and Nanofabrication, 2008, San Jose, California, United States 


\section{PROCEEDINGS OF SPIE}

\section{MOEMS and Miniaturized Systems VII}

David L. Dickensheets

Harald Schenk

Editors

22-23 January 2008

San Jose, California, USA

Sponsored by

SPIE

Cosponsored by

The Photonics Center at Boston University (USA)

Published by

SPIE

Volume 6887 
The papers included in this volume were part of the technical conference cited on the cover and title page. Papers were selected and subject to review by the editors and conference program committee. Some conference presentations may not be available for publication. The papers published in these proceedings reflect the work and thoughts of the authors and are published herein as submitted. The publisher is not responsible for the validity of the information or for any outcomes resulting from reliance thereon.

Please use the following format to cite material from this book:

Author(s), "Title of Paper," in MOEMS and Miniaturized Systems VII, edited by David L. Dickensheets, Harald Schenk, Proceedings of SPIE Vol. 6887 (SPIE, Bellingham, WA, 2008) Article CID Number.

ISSN 0277-786X

ISBN 9780819470621

Published by

SPIE

P.O. Box 10, Bellingham, Washington 98227-0010 USA

Telephone +1 3606763290 (Pacific Time) · Fax +1 3606471445

SPIE.org

Copyright (C 2008, Society of Photo-Optical Instrumentation Engineers

Copying of material in this book for internal or personal use, or for the internal or personal use of specific clients, beyond the fair use provisions granted by the U.S. Copyright Law is authorized by SPIE subject to payment of copying fees. The Transactional Reporting Service base fee for this volume is $\$ 18.00$ per article (or portion thereof), which should be paid directly to the Copyright Clearance Center (CCC), 222 Rosewood Drive, Danvers, MA 01923. Payment may also be made electronically through CCC Online at copyright.com. Other copying for republication, resale, advertising or promotion, or any form of systematic or multiple reproduction of any material in this book is prohibited except with permission in writing from the publisher. The CCC fee code is $0277-786 \mathrm{X} / 08 / \$ 18.00$.

Printed in the United States of America.

Publication of record for individual papers is online in the SPIE Digital Library.

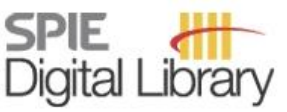

SPIEDigitallibrary.org

Paper Numbering: Proceedings of SPIE follow an e-First publication model, with papers published first online and then in print and on CD-ROM. Papers are published as they are submitted and meet publication criteria. A unique, consistent, permanent citation identifier (CID) number is assigned to each article at the time of the first publication. Utilization of CIDs allows articles to be fully citable as soon they are published online, and connects the same identifier to all online, print, and electronic versions of the publication. SPIE uses a six-digit CID article numbering system in which:

- The first four digits correspond to the SPIE volume number.

- The last two digits indicate publication order within the volume using a Base 36 numbering system employing both numerals and letters. These two-number sets start with 00, 01, 02, 03, 04, 05, $06,07,08,09,0 A, 0 B \ldots 0 Z$, followed by $10-12,20-2 Z$, etc.

The CID number appears on each page of the manuscript. The complete citation is used on the first page, and an abbreviated version on subsequent pages. Numbers in the index correspond to the last two digits of the six-digit CID number. 


\title{
Contents
}

\author{
vii Conference Committee \\ ix MEMS reliability: coming of age (Plenary Paper) [6884-30] \\ M. R. Douglass, Texas Instruments (USA)
}

\section{SESSION 1 DISPLAY APPLICATIONS}

688702 A novel diffractive micro-optical modulator for mobile display applications (Invited Paper) [6887-01]

S. K. Yun, J. Song, S. An, I. Yeo, Y. Choi, Y. Lee, H. Park, K. Han, H. Yang, V. Yurlov, I. Shyshkin, A. Lapchuk, H. Kim, J. Jang, J. Kyoung, J. Yang, S. Yoon, C. Park, J. Cheong, Y. Hwang, K. Woo, S. Ryu, S. Lee, C. Koh, Y. Baek, D. Bae, H. Lee, J. Lee, Y. Ryu, H. Hwang, C. Yang, O. Lim, D. Park, S. An, J. Bae, S. Cho, B. Go, S. Hong, H. Jung, S. Kim, K. Lee, J. Park, J. Yang, G. Byun, S. Byun, Y. Cho, C. Kim, J. Kim, S. Kim, S. Lee, W. Lee, K. Oh, S. Oh, W. Shin, B. Song, E. Bourim, Samsung Electro-Mechanics Co. (South Korea)

688703 Two dimensional microscanners with large horizontal-vertical scanning frequency ratio for high-resolution laser projectors (Invited Paper) [6887-02]

S.-T. Hsu, T. Klose, C. Drabe, H. Schenk, Fraunhofer Institute for Photonic Microsystems (Germany)

688704 Slow scanning electromagnetic MEMS scanner for laser display [6887-03] H.-M. Jeong, Y.-H. Park, H.-K. Jeong, Y.-C. Cho, S.-M. Chang, J.-O Kim, S.-J. Kang, J.-S. Hwang, J.-H. Lee, Samsung Advanced Institute of Technology (South Korea)

$688705 \quad$ Flat electrowetting optics and displays [6887-04]

J. C. Heikenfeld, N. R. Smith, B. Sun, K. Zhou, L. Hou, Y. Lao, B. Raj, Univ. of Cincinnati (USA)

\section{SESSION 2 OPTICAL ASSEMBLY AND PACKAGING}

688706 Wafer-level vacuum packaged resonant micro-scanning mirrors for compact laser projection displays (Invited Paper) [6887-05]

U. Hofmann, M. Oldsen, H.-J. Quenzer, J. Janes, Fraunhofer Institute for Silicon Technology (Germany); M. Heller, SensorDynamics AG (Germany); M. Weiss, G. Fakas, L. Ratzmann, Fraunhofer Institute for Silicon Technology (Germany); E. Marchetti, F. D'Ascoli, M. Melani, L. Bacciarelli, E. Volpi, F. Battini, L. Mostardini, F. Sechi, M. De Marinis, SensorDynamics AG (Italy); B. Wagner, Fraunhofer Institute for Silicon Technology (Germany)

688707 Development of wafer level packaged scanning micromirrors (Invited Paper) [6887-06] A. Yu, Institute of Microelectronics (Singapore); C. Lee, Institute of Microelectronics (Singapore) and National Univ. of Singapore (Singapore); L. L. Yan, Q. X. Zhang, S. U. Yoon, J. H. Lau, Institute of Microelectronics (Singapore) 
688708 A biocompatible miniaturized package housing for a 3D micromirror-based optical bioprobe for OCT imaging application [6887-07]

C. S. Premachandran, A. Khairyanto, K. Chen, J. Singh, Institute of Microelectronics (Singapore)

\section{SESSION 3 IMAGING APPLICATIONS}

688709 Advanced artificial compound-eye imaging systems [6887-08]

A. Brückner, J. Duparré, A. Bräuer, Fraunhofer Institute for Applied Optics and Precision Engineering (Germany)

6887 OA MEMS-based optoelectronic system for distance measurement applicable for panorama cameras [6887-09]

M. Schaulin, Technische Univ. Dresden (Germany); J. Knobbe, H. Neumann, K. Seidl, L. Kleinmann, U. Schelinski, M. Scholles, Fraunhofer-Institut für Photonische Mikrosysteme (Germany); H.-J. Schönherr, Kamera and System Technik GmbH (Germany); H. Lakner, Technische Univ. Dresden (Germany)

6887 OB Micromirrors for multiobject spectroscopy: optical and cryogenic characterization [6887-10]

S. Waldis, Univ. of Neuchatel (Switzerland); F. Zamkotsian, P. Lanzoni, Lab. d'Astrophysique de Marseille (France); W. Noell, N. de Rooij, Univ. of Neuchatel (Switzerland)

\section{SESSION 4 MICROSPECTROMETERS AND OPTICAL FILTERS}

6887 OC A porous silicon thermally tunable optical filter (Invited Paper) [6887-11]

D. Song, N. Tokranova, A. Gracias, J. Castracane, Univ. at Albany, State Univ. of New York (USA)

6887 OD Dual-detector optical MEMS spectrum analyzer: advances, applications, and prospects [6887-12]

T. Otto, R. Saupe, Fraunhofer Institute for Reliability and Microintegration (Germany);

A. Weiss, Chemnitz Univ. of Technology (Germany); V. Stock, Colour Control Farbmesstechnik GmbH (Germany); K. Wiesner, U. Lampe, M. Fleischer, Siemens AG (Germany); T. Gessner, Fraunhofer Institute for Reliability and Microintegration (Germany) and Chemnitz Univ. of Technology (Germany)

6887 OE Pushbroom NIR hyperspectral imager using MOEMS scanning grating chips [6887-13] H. Grüger, T. Egloff, M. Scholles, F. Zimmer, M. Müller, H. Schenk, Fraunhofer-Institut für Photonische Mikrosysteme (Germany)

\section{SESSION 5 MOEM COMPONENTS AND SYSTEMS I}

6887 OF 3D MOEMS-based optical micro-bench platform for the miniaturization of sensing devices (Best Paper Award) [6887-14]

S. Garcia-Blanco, J.-S. Caron, S. Leclair, P. A. Topart, H. Jerominek, INO (Canada)

6887 OG Novel optical viscosity sensor using laser-induced capillary wave [6887-15]

A. Ebisui, Y. Taguchi, Y. Nagasaka, Keio Univ. (Japan) 
$6887 \mathrm{OH}$ Radiation-pressure effects upon a micromirror in a high-finesse optical cavity [6887-16] A. Heidmann, O. Arcizet, C. Molinelli, T. Briant, P.-F. Cohadon, Lab. Kastler Brossel, Univ. Pierre et Marie Curie, CNRS (France)

6887 Ol One-axis metallic electrostatic micromirror array [6887-17]

K. Tondapu, Q. Cheng, M. Almasri, Univ. of Missouri, Columbia (USA)

\section{POSTER SESSION}

6887 OK Mobile flat mirrors for micro-optical scanners [6887-20]

G. Molar-Velázquez, F. J. Renero-Carrillo, W. Calleja-Arriaga, Instituto Nacional de Astrofísica, Óptica y Electrónica (Mexico)

$6887 \mathrm{OL} \quad$ New approach for MEMS scanning mirror for laser projection systems [6887-21]

H. Grüger, J. Knobbe, M. Scholles, H. Schenk, H. Lakner, Fraunhofer-Institut für Photonische Mikrosysteme (Germany)

Author Index 
Downloaded From: https://www.spiedigitallibrary.org/conference-proceedings-of-spie on 25 Apr 2023

Terms of Use: https://www.spiedigitallibrary.org/terms-of-use 


\title{
Conference Committee
}

\author{
Symposium Chair
}

Albert K. Henning, Nanolnk, Inc. (USA)

Symposium Cochair

Thomas J. Suleski, University of North Carolina at Charlotte (USA)

Conference Chairs

David L. Dickensheets, Montana State University, Bozeman (USA)

Harald Schenk, Fraunhofer Institute for Photonic Microsystems

(Germany)

Program Committee

Susanne Arney, Lucent Technologies, Bell Laboratories (USA)

Jean-Christophe Eloy, Yole Dévelopment (France)

Wilfried Noell, University of Neuchâtel (Switzerland)

Yong-Hwa Park, Samsung Advanced Institute of Technology (South Korea)

Wibool Piyawattanametha, Stanford University (USA) and

NECTEC (Thailand)

Hakan Ürey, Koç University (Turkey)

Session Chairs

1 Display Applications

David L. Dickensheets, Montana State University, Bozeman (USA)

2 Optical Assembly and Packaging

Wibool Piyawattanametha, Stanford University (USA) and NECTEC (Thailand)

3 Imaging Applications

David L. Dickensheets, Montana State University, Bozeman (USA)

$4 \quad$ Microspectrometers and Optical Filters

Wilfried Noell, University of Neuchâtel (Switzerland)

5 MOEM Components and Systems I

Thilo Sandner, Fraunhofer Institute for Photonic Microsystems

(Germany)

Sonia Garcia-Blanco, Institut National d'Optique (Canada) 
Downloaded From: https://www.spiedigitallibrary.org/conference-proceedings-of-spie on 25 Apr 2023

Terms of Use: https://www.spiedigitallibrary.org/terms-of-use 


\title{
MEMS Reliability - Coming of Age
}

\author{
Michael R. Douglass \\ Texas Instruments, 6550 Chase Oaks Blvd, Plano, Texas, USA
}

\begin{abstract}
In today's high-volume semiconductor world, one could easily take reliability for granted. As the MOEMS/MEMS industry continues to establish itself as a viable alternative to conventional manufacturing in the macro world, reliability can be of high concern. Currently, there are several emerging market opportunities in which MOEMS/MEMS is gaining a foothold. Markets such as mobile media, consumer electronics, biomedical devices, and homeland security are all showing great interest in microfabricated products. At the same time, these markets are among the most demanding when it comes to reliability assurance. To be successful, each company developing a MOEMS/MEMS device must consider reliability on an equal footing with cost, performance and manufacturability.

What can this maturing industry learn from the successful development of DLP ${ }^{\circledR}$ technology, air bag accelerometers and inkjet printheads? This paper discusses some basic reliability principles which any MOEMS/MEMS device development must use. Examples from the commercially successful and highly reliable Digital Micromirror Device complement the discussion.
\end{abstract}

Keywords: MEMS, MOEMS, Reliability, FMEA, Accelerated Testing, Stress Testing

\section{RELIABILITY: A BUILDING BLOCK}

Consumers often focus on price while assuming the product is reliable. After all, why would a company sell a product that is not reliable? Because of the consumer's focus on price, some businesses may overlook the importance of including reliability as a fundamental building block along with cost and performance. The absence of reliability can lead to disastrous consequences. Lives are lost in the worst case. Businesses fail, profits fall and reputations are tainted in less critical situations. Is a $99 \%$ success rate good enough in our daily lives? In some cases this may be acceptable whereas in other cases, probably not. Airlines proudly report a success rate of greater than $99 \%$ in getting luggage to its destination. Based on a recent report, one in every 138 checked bags was lost or misdirected in 2007. This may seem like a robust process, $99.3 \%$ success rate, but it results in close to five million passengers impacted by misrouted luggage [1]. Would this be good enough for flight controllers? DFW Airport handles nearly 700,000 flight operations per year [2]. A $99.3 \%$ success rate resulting in 5,000 misdirected aircraft per year would be a serious safety risk and completely unacceptable. Based on cost versus risk, airports have developed a much more robust and reliable system for handling aircraft operations than has been developed for baggage handling. Consumers demand it.

What is an acceptable success rate for a system, device or process? This depends on numerous factors the most important of which is the customers' expectations. Understanding and meeting customer expectations is paramount to building a good relationship. MEMS devices are often uniquely suited to meeting a customer's reliability needs but the challenge is proving it. The Digital Micromirror Device (DMD), a digital optical MEMS technology at the heart of DLP $^{\circledR}$ televisions, cinemas, and projectors [3], demonstrates MEMS reliability on a daily basis. DMDs in these applications rarely have even 1 pixel defect through thousands of hours of operation thus demonstrating mirror reliability greater than $99.9999 \%$.

After many years of predicting growth in the MOEMS/MEMS, industry, growth is finally occurring. There are many examples of growing successful MEMS businesses besides the well-known DMD in DLP projection applications and accelerometers in automobile air bags. Figure 1 shows the top 30 MEMS manufacturers in 2006. Consumer markets are growing rapidly although most consumers are probably not even aware of them. Inkjet printheads have been using MEMS for years. MEMS gyroscopes have been widely integrated into camcorders since 1998 to provide optical stabilization. Hard disk drives have used MEMS accelerometers as a protection feature since 2003. In 2006, Nintendo

Reliability, Packaging, Testing, and Characterization of MEMS/MOEMS VII, edited by Allyson L. Hartzell, Rajeshuni Ramesham, Proc. of SPIE Vol. 6884, 688402, (2008) · 0277-786X/08/\$18 · doi: 10.1117/12.791010 
introduced the Wii interactive computer game to the public incorporating inertial MEMS sensors [4]. None of this would be possible without cost, performance and reliability advances.

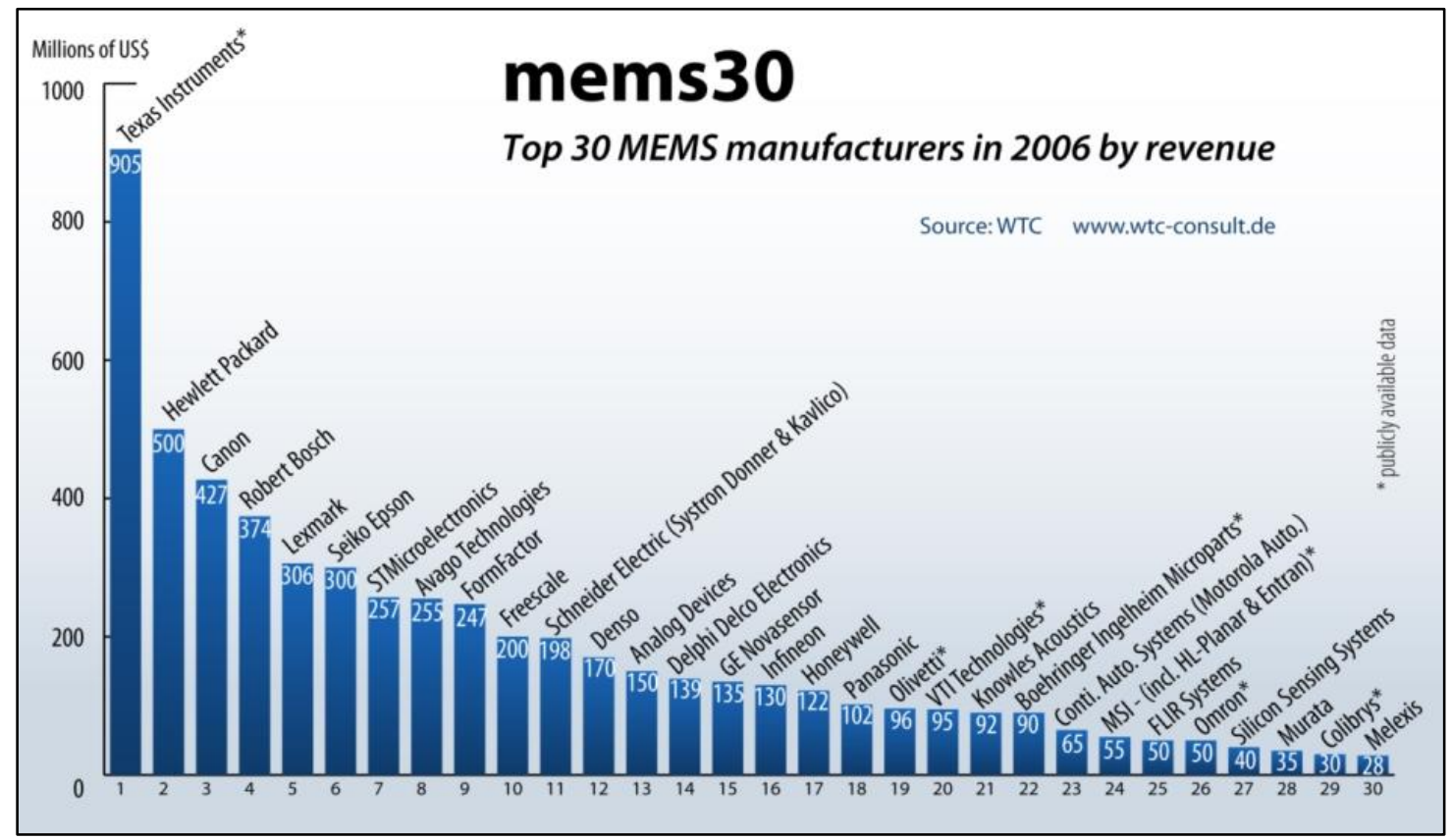

Figure 1 - Top 30 MEMS manufacturers in 2006 by revenue. The top products include optical MEMS (TI), inkjet printheads (HP, Canon, Lexmark, Seiko Epson, STMicroelectronics, and Olivetti), and automotive products (Bosch).

\section{THE SYSTEM RELIABILITY DEVELOPMENT PROCESS}

Since MEMS devices are micro-systems, the concepts developed by systems reliability engineers apply directly to MEMS. Many of these concepts originated to support the high reliability demands of military electronics. Over the years, commercial products adopted and adapted the concepts to address the increased demand for reliability in the consumer space. Now, the MEMS industry is following the same path by focusing on the methods rather than any specific tests.

For example, the much maligned [5] and often overused bathtub curve shown in Figure 2 is an excellent way to take a complicated system, either macro or micro, and break it down into discrete segments. The focus should not be on the

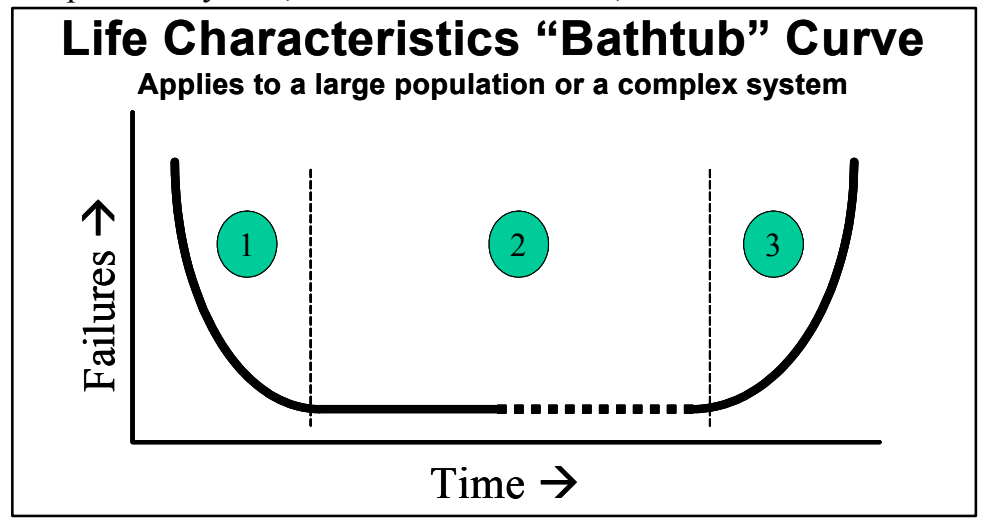

Figure 2 - The classic bathtub curve with 3 distinct segments: (1) early failures, (2) useful life, and (3) wear out or end-of-life. statistical accuracy of the curve but on the segmentation of the problem. Regardless of the statistics, engineers must determine the root cause of failures and continuously improve reliability in product design and manufacturing techniques. As much as we would like to have no failures over a fixed period of time, as shown in Figure 3, it will rarely happen in practice. There will be yield fallout in production, there will be a number of escapes through the inspection and test process resulting in early customer failures, there will be some weaker devices fail during use due to overstress, and there will eventually be failures due to wear out. 
A large population of complicated systems tends to follow the bathtub relationship. Each segment of a system's life cycle requires a different corrective action approach. For example, more effective burn-in testing or stress screening can identify early failures in segment 1 of Figure 2. Any defective units that make it through the production test will result in

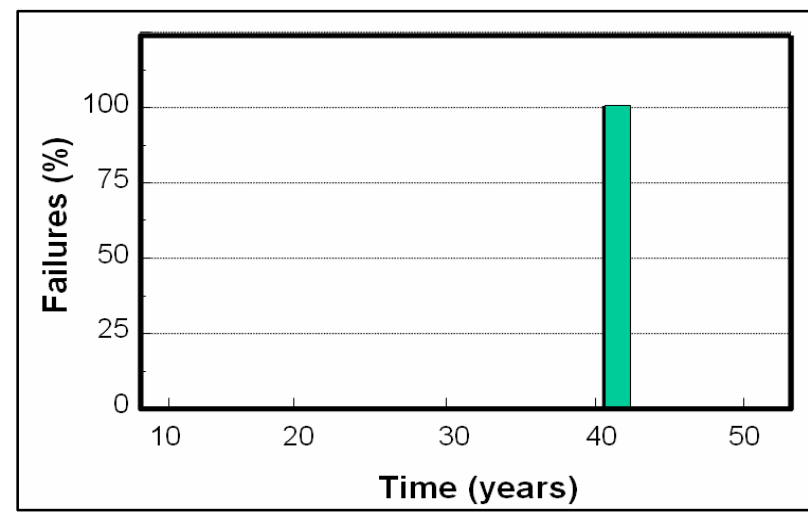

Figure 3 - The ideal bathtub curve. No failures for 40 years then everything fails the next day. a customer failure. A customer's production test will often catch defects but some will still escape resulting in an enduser failure. An example of reducing defects with the DMD involved improved correlation of inspection criteria. Since the DMD displays an image, the criteria for acceptance include visual inspection of the displayed image in the customers' product. Test equipment correlation as well as inspection operator training resulted in an order of magnitude improvement in Texas Instruments' outgoing quality as measured by the customers' production yield. Segment 2 of the bathtub curve is usually difficult to understand and improve. The most effective approach is to design the product for the worst-case intended application. A more robust design survives, not only the intended use, but abusive use as well. The challenge is to not over-design and add unnecessary costs to the product. Conservative engineers like to design to the worst, worst, worst-case condition. This will almost assuredly result in a product with a cost structure that will not support the intended application. Designing for a typical consumer, not the few consumers that might use the product in extreme cold or extreme heat, is often the most effective approach. Exceptions may include medical applications or space applications where failure is not acceptable under any circumstances.

To address lifetime issues in segment 3, designers can select different materials that last longer before wearing out. Other options include defining drive circuits that extend lifetime, and adding redundant systems. Are all of these actions required? It depends on the cost versus risk analysis and what the customers' requirements are. It is imperative that the reliability of any system take into account the risks in each segment of the bathtub curve and address them appropriately. Otherwise, the results will be customer dissatisfaction, excessive warranty costs and/or a bad reputation.

\section{IDENTIFYING AREAS OF RISK}

A Failure Modes and Effects Analysis (FMEA) is typically a requirement for developing military equipment due to the complex nature of the systems. FMEA involves brainstorming potential failure modes, identifying associated root causes, assigning levels of risk (severity, detectability, and occurrence), and following through with corrective actions. Component development does not often use the approach. Since MEMS devices are literally systems, albeit on a microscale, the FMEA approach has proved to be an effective method of identifying potential failure modes and mechanisms [6]. Early development of the DMD utilized FMEA as a way to partition the complex system into specific areas of risk. This allowed TI to prioritize and focus on the areas of greatest concern $[7,8]$.

Each MEMS technology may have some unique failure modes and mechanisms that set it apart from other MEMS or solid-state electronic technologies. Therefore, the FMEA methodology should be customized to account for these unique differences, prioritizing them according to their overall significance within the realm of more traditional failure modes and mechanisms. Depending on the MEMS technology, examples may include packaging concerns, stiction, particle sensitivity, wear, chemical interactions, or mechanical shock integrity. The more thorough the FMEA, the better one can establish a reliability plan to ensure device robustness.

NASA guidelines for MEMS development use the same approach as described above. For example, JPL Publication 991, "MEMS Reliability Assurance Guidelines for Space Applications" [9] specifically states, "The focus of this guide is upon methods rather than tests..." and "...the vast difference in types of MEMS devices means that each set of devices may require unique acceleration conditions." Increasing temperature in solid-state electronic systems will accelerate failure mechanisms. "In MEMS...it may be temperature, humidity, vibration, or a number of other factors that limit device lifetime and accelerating one failure mode may decelerate another [9]." That last statement, in particular, succinctly summarizes the challenges associated with MEMS reliability. A more recent publication states that, "...the 
failure modes of MEMS can be very different from those of solid-state electronics. Therefore testing techniques must be developed to accelerate MEMS-specific failures [10]." The importance of using a structured approach like FMEA cannot be overstated. Regarding the DMD, TI developed many unique tests as a result of the FMEA process.

Not only are there unique failure mechanisms associated with MEMS architectures, but also MEMS materials and manufacturing methods have unique characteristics. Tronics Microsystems documented an example where the production yield of an inertial device increased from $43 \%$ to $67 \%$ within 2 years through the systematic analysis of 17 identified failure modes [11]. FMEA can be applied to a foundry process to highlight manufacturing weaknesses throughout the entire production loop. Statistical Process Control (SPC) is an excellent way to address concerns highlighted by the FMEA [11].

An interesting aspect of MEMS devices is that they all interact with the environment in some manner. The DMD converts an analog light source into digital pixels for high quality displays. Automobiles use accelerometers, tire pressure sensors, and stability control to interpret and respond to the environment. The medical industry uses nanopumps to deliver drugs to patients. The reliability engineer must consider all these unique applications very carefully. The best approach is to assemble a group of experts from diverse disciplines, the more diverse, the better the FMEA. Brainstorm all possible failure modes and failure mechanisms. How can the device fail? When will it fail? When it fails, what happens? What is the impact to the system and to the user? Some people find this process invigorating while others find it frustrating to focus exclusively on the negative aspects of the design. Certainly, a properly managed FMEA is an educational experience where everyone in the room learns about the inner workings of the device.

The most important aspect of an FMEA is the follow-up and corrective action closure. If a team does an excellent job of brainstorming and stops there, the entire process was a waste of time. Discuss and rank each concern. Determine which ones need immediate attention. Establish an action plan to address each concern: analysis, design, inspection, or test. Then close the loop on the FMEA by updating the concerns with the actions taken.

\section{FAILURE LEADS TO SUCCESS}

To understand the robustness of a design and to thoroughly explore the items identified in the FMEA, you must find failure limits. A critical methodology used by systems reliability engineers that must also be applied to MEMS is the test-to-failure philosophy that includes the maxim to continually explore the design limits of the product. Some quotes from "Success through Failure" [12] follow:

"The Paradox of Design: Things that succeed teach us little beyond the fact that they have been successful; things that fail provide incontrovertible evidence that the limits of design have been exceeded. Emulating success risks failure; studying failure increases our chances of success."

"When failure is left behind, success leads with a confidence that the uncharted future does not warrant."

"A profession that never has accidents is unlikely to be serving its country efficiently."

"Given the faults of human nature, coupled with the complexity of the design of everything...it behooves us to beware of the lure of success and to listen to the lessons of failure."

New technologies, such as MEMS, are ripe for exploring design limits similar to those shown in Figure 4. Whether the stress is temperature, voltage, vibration, or shock, knowing where a device ceases to function (operating margin) and where permanent damage occurs (destruct margin) is invaluable. For example, if the device maximum operating specification is $65^{\circ} \mathrm{C}$ and stress testing demonstrates continued operation up to $85^{\circ} \mathrm{C}$, then you know there is substantial margin. If the device fails at $70^{\circ} \mathrm{C}$, then there is a chance of customer failure and also a distinct risk that process variation will result in some future lots failing even when operated within specification limits. In this case, the designers should implement a corrective action. Likewise, if the device can be exposed to $100^{\circ} \mathrm{C}$ without permanent damage, there is substantial margin but if the device is damaged when exposed to $70^{\circ} \mathrm{C}$, then it is likely to fail in a customer's application resulting in dissatisfaction. While exploring the design limits in response to an FMEA concern, engineers 
often uncover unexpected failure mechanisms. This occurred frequently during DMD development. Finding failures early helped speed the development process and ended with a robust design delivered to customers. The DMD philosophy was, and still is, that "every failure is an opportunity to learn" and that "the only bad test is a test where you don't learn anything [8]."

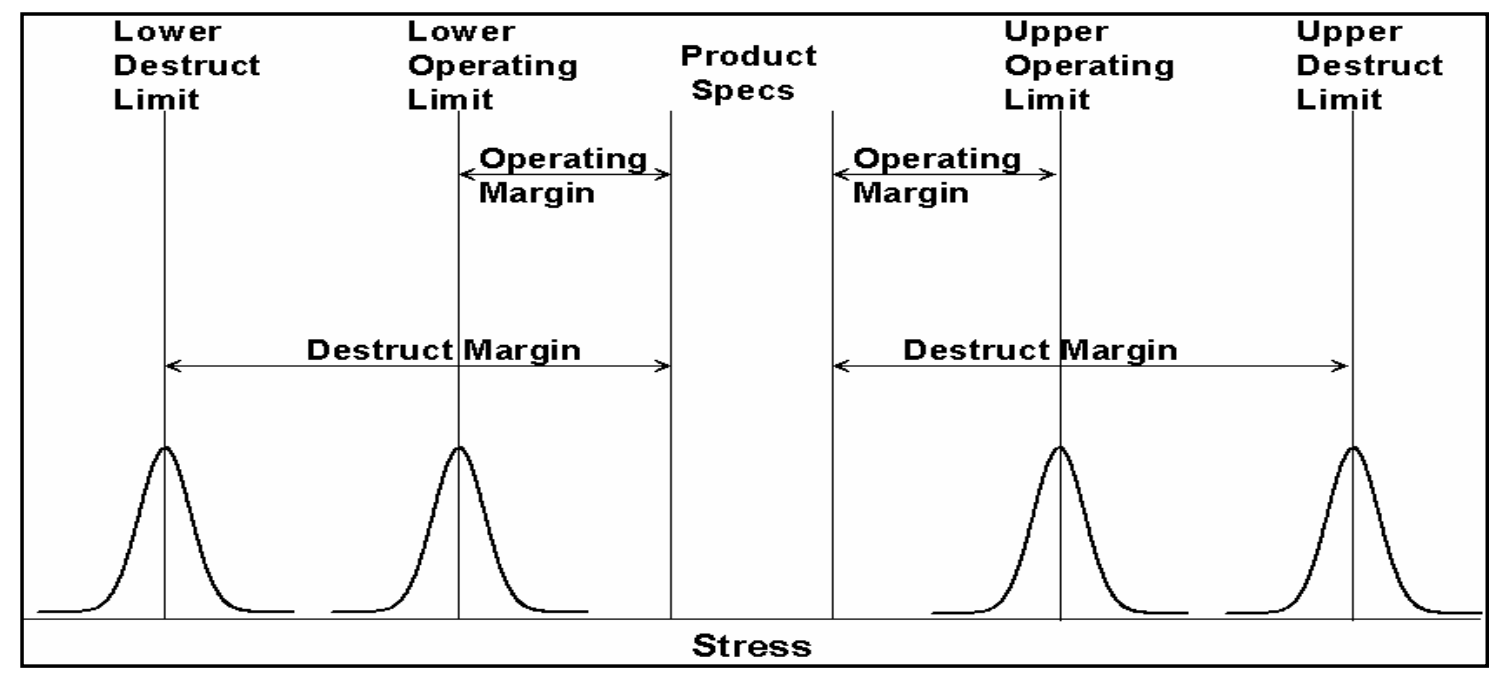

Figure 4 - Accelerated Stress Testing or Test-to-Failure Approach.

\section{ACCELERATED STRESS TESTING}

Accelerated testing is an excellent method to highlight weaknesses and determine how much margin the device has to its intended use conditions. The approach is to test-to-failure, find the weaknesses, evaluate the root cause, determine if the corrective action is practical, analyze the risk/benefit ratio of implementing the corrective action, and updating the FMEA as shown in Figure 5.
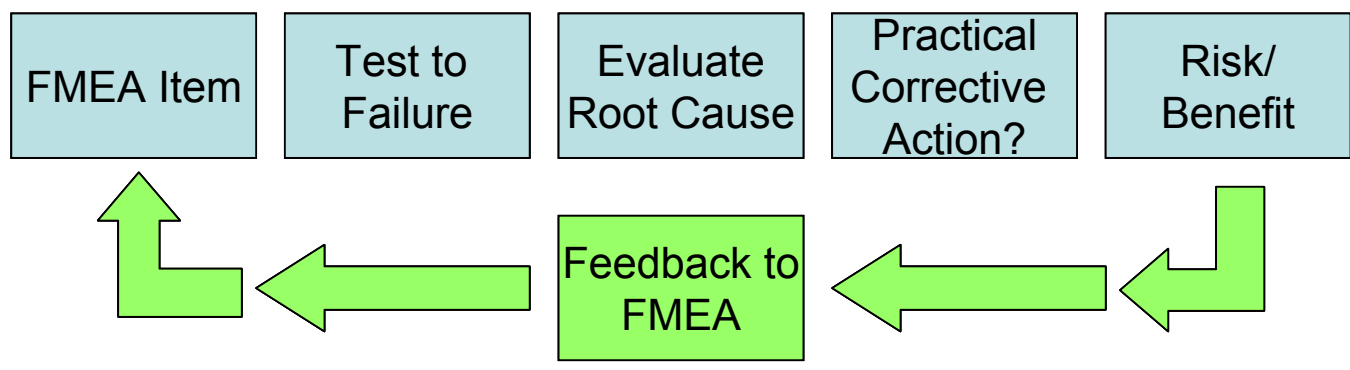

Figure 5 - Test-to-Failure approach with closed-loop feedback to the FMEA.

A survey performed by the MEMS Industry Group (MIG) in 2004 found that " $70 \%$ of MEMS designers and suppliers perform accelerated life testing [13]." The survey also found that, "Over $80 \%$ of those surveyed indicated...that average lifetime for a MEMS device is 15 years." One question comes to mind; if the MEMS industry measures lifetime in years and $30 \%$ of the MEMS industry is not using accelerated life testing techniques, how are they demonstrating their reliability? Computer simulation is a possibility but its accuracy is limited without test data to support it and refine it. What is the best way to demonstrate the reliability of your product, first to yourself and then to a potential customer? For lifetimes measured in years, the only practical method is accelerated life testing or accelerated stress testing.

Throughout the early development of the DMD, accelerated life testing was used extensively as it still is today. One example addressed an early FMEA concern about the hinge. Several DMDs started an accelerated life test in December 
1995. They were tested most recently in December 2007. After 12 years and over 100,000 actual operating hours, there have been no hinge fatigue failures. This is an accelerated test where the mirrors are cycled much faster than in normal operation. Each DMD mirror has cycled from on-to-off $5.30 \times 10^{\wedge} 12$ times throughout the test which is equivalent to over 360,000 operating hours without a fatigue failure. The 9 DMDs on test each have 500,000 mirrors; each mirror has cycled $5.30 \times 10^{\wedge} 12$ times for a total of $23.9 \times 10^{\wedge} 18$ mechanical movements.

These are impressive numbers but what do they mean? One conclusion is that micromechanics behave differently than macromechanics. This was critical to developing the DMD. Early models predicted the mirrors would fail due to fatigue cracks after several billion cycles. The test-to-failure approach quickly demonstrated that MEMS behave in a fundamentally different way. This led to a better understanding of thin film properties and the theory that stresses are relieved on the surface of amorphous micro-structures instead of at grain boundaries in macro-structures. Without using the test-to-failure approach, this important finding would have been missed.

Other accelerated stress tests have had equally interesting findings. Vibration and shock testing of the DMD confirmed that micromirrors are effectively immune to mechanical motions in the kilohertz range or less since the mirrors' resonant response is in the range of $100 \mathrm{KHz}$ to $2 \mathrm{MHz}$ or higher depending on the resonant mode and whether the mirror is in the unenergized (flat) state or is at the actuated angle of \pm 12 degrees. As a result, DMDs are robust during normal handling and assembly processes. In addition, DMD environmental qualification tests (Table 1) are able to use stresses well beyond typical applications as a method of finding design or process weaknesses. Through the use of thermal shock and temperature cycling, TI found window seal problems with early DMD packages and eliminated them prior to production. Maintaining the environment inside a MEMS package can be a concern for some devices. Sandia National Labs found that too much humidity can cause failures, as expected, but surprisingly, too little moisture can also cause defects [14].

\begin{tabular}{|l|l|l|}
\hline Qualification Test & \multicolumn{1}{|c|}{ Test Description } & \multicolumn{1}{|c|}{$\begin{array}{c}\text { Hours/Cycles } \\
\text { (minimum) }\end{array}$} \\
\hline Storage Life Cold/Hot & $-55 / 100 \mathrm{C}$, no power & 1000 hours \\
\hline Temperature Cycle & $-55 / 125 \mathrm{C}$, air-to-air, fine/gross leak & 1000 cycles \\
\hline Thermal Shock & $-55 / 125 \mathrm{C}$, liquid-to-liquid & 200 cycles \\
\hline Sequence 1 & $\begin{array}{l}1500 \mathrm{~g} \text { Mechanical Shock, Y only } \\
\text { Vibration, 20g, 20-2000Hz } \\
\text { Constant Acceleration, 10Kg, Y1 only }\end{array}$ & \\
\hline Sequence 2 & $\begin{array}{l}\text { Thermal Shock, }-55 / 125 \mathrm{C} \\
\text { Temperature Cycles, -55/+125C } \\
\text { Moisture Resistance }\end{array}$ & $\begin{array}{l}15 \text { cycles } \\
100 \text { cycles } \\
10 \text { days }\end{array}$ \\
\hline
\end{tabular}

Table 1 - Typical DMD environmental tests

The most impressive accelerated stress test ever performed on a complete DLP system was the one performed by Raytheon Systems Company in 1997. They used a Highly Accelerated Life Testing (HALT) approach to validate that their rugged display could survive stringent military environments. Tests on the entire display system included cold operation down to $-71^{\circ} \mathrm{C}$, hot operation up to $+97^{\circ} \mathrm{C}$, thermal shock cycles from $-80^{\circ} \mathrm{C}$ to $+100^{\circ} \mathrm{C}$ at a rate up to $60^{\circ} \mathrm{C}$ per minute, and 3 -axis random vibration up to $45 \mathrm{Grms}$. The tests uncovered some minor design flaws but the display performed well in excess of the customer's expectations. The components comprising the DLP technology portion of the display (DMD, color wheel, and ASICs) performed flawlessly throughout the test [15]. TI does not recommend using DLP projectors in such a severe environment but it is good to know that they can survive, thanks in part to the MEMS device at the heart of the system.

TI has drawn an interesting conclusion from MEMS test results over the years as have other MEMS manufacturers MEMS devices are robust because they are small. At first this seems to go against common sense but not if one considers the appropriate scaling laws. For example the strength to weight ratio scales as area over weight $\left(1^{2} / 1^{3}=1^{-1}\right)$. This is the reason an ant can carry many times its own weight, whereas a human cannot. 
Discera developed a MEMS oscillator for a high-reliability military application. The oscillator has already survived shock testing up to $14,000 \mathrm{~g}$ with simulations predicting survival up to $100,000 \mathrm{~g}$. Discera contends the superior shock resistance is due to "the MEMS oscillator's gravity-defying weight [16]." ADI states that MEMS gyroscopes are smaller, use much less power, and are more tolerant to vibration than their macro-counterparts. "Their immunity to vibration and shock comes from their being so small that their resonant frequency is very high...compared to normal gyros [17]." So it appears that MOEMS/MEMS devices may actually have a fundamental reliability advantage over their macro counterparts.

\section{COMPETITIVE ASSESSMENT}

It is critically important to understand the competitive landscape including competitive reliability. There are several questions that need to be considered as a company enters new markets or tries to grow existing market share:

1. Do you have a competitive advantage or disadvantage?

2. Is your product over-designed or under-designed for its application?

3. Are you meeting or exceeding your customers' expectations?

4. Are there related markets where reliability is valued more or less?

By gaining a better understanding of the competition and the market in general, a business can determine future strategies. In some cases, one can gain market share through improved advertising and marketing, in other cases, one might determine that the product is over-designed for its intended application and therefore too costly.

In the case of the DMD and DLP technology, an assessment of competitive technologies highlighted a significant advantage in applications requiring long life under high stress conditions (e.g., high temperature, bright light, and continuous operation.) Compared to analog technologies, a digital optical MEMS technology has exceptional stability of image quality over time. Because the MEMS structure is operating in a digital mode, it is not sensitive to the analog changes in its structure that may develop, until those changes reach a level that cause a switching failure or "hard" defect.

The bottom line then is to design and manufacture the DMD so that at the end of its expected lifetime under the harshest of operating conditions, there is still (digital) operating margin to spare. So instead of failing "gracefully" like analog technologies, it doesn't fail at all [3]. This life characteristic is an example of the ideal bathtub curve in Figure 3.

Other MEMS devices have distinct advantages in reliability, size, weight, power consumption and other performance parameters. For example, Hewlett Packard touts the reliability of their MEMS-based inkjet printhead in a brochure where they say they have brought together "proven silicon-based Micro Electro-Mechanical Systems (MEMS) technology and innovative piezoelectric inkjet technology... The new printhead is highly durable and reliable... [18]." Another interesting statement in this reference is, "MEMS technology was imported from semiconductor fabrication methods. It enables micron-scale mechanical and electrical components to be built on a silicon chip." The use of existing semiconductor tool sets, processes and methodologies is another advantage of MEMS. Even packaging, historically a challenge for MOEMS/MEMS, is taking advantage of the cost-effectiveness and broad availability of CMOS processing technology to develop packaging techniques [19]. The infrastructure and knowledge is in place to rapidly reach the reliability levels already achieved by the mature semiconductor industry. The key for each MOEMS/MEMS device will be to identify its differentiating feature(s), achieve parity on other features (like cost), and prepare for entry into a competitive market.

\section{CONCLUSION}

MOEMS/MEMS devices are becoming more commonplace every day. Consumers will demand high reliability along with performance and pricing pressure. So far, the industry as a whole has responded appropriately. There are numerous examples of MOEMS/MEMS devices with excellent reliability resulting from well-designed products and wellstructured reliability approaches. There is nothing that makes developing MOEMS/MEMS any more challenging than mature technologies other than there are more unknowns to discover. If the MOEMS/MEMS industry continues to use the reliability development methods that have been successfully applied to mature technologies, the journey will continue to be an exciting and rewarding adventure for all involved. 


\section{REFERENCES}

1. J. Bailey, "Travelers' Odds Decline on Airline Baggage," The New York Times, November 21, 2007.

2. See www.dfwairport.com

3. L. Hornbeck, "Combining Digital Optical MEMS, CMOS, and Algorithms for Unique Display Solutions," IEEE International Electron Devices Meeting Technical Digest, pp. 17-24, 2007.

4. Yole Development, "World Inertial Sensors Markets: Accelerometers and Gyroscopes for Consumer Applications," Research Report \# YD4264-2, September 2007

5. G. Klutke, P. Kiessler, and M. Wortman, "A Critical Look at the Bathtub Curve," IEEE Transactions on Reliability, Vol. 52, No. 1, March 2003.

6. S. Bhattacharya and A. Hartzell, "Optical Microelectromechanical Systems: Designing for Reliability," $J$. Micro/Nanolith. MEMS MOEMS, Vol. 6(3), 2007.

7. M. Douglass, "Lifetime Estimates and Unique Failure Mechanisms of the Digital Micromirror Device (DMD)," Proceedings of International Reliability Physics Symposium, pp. 9-16, 1998.

8. M. Douglass, "DMD Reliability: A MEMS Success Story," (Keynote Address), Proceedings SPIE, Vol. 4980, Reliability, Testing, and Characterization of MEMS/MOEMS II, 2003.

9. B. Stark (Editor), "MEMS Reliability Assurance Guidelines for Space Applications", JPL Publication 99-1, January 1999.

10. A. Dommann, G. Kotrotsios, and A. Neels, "MEMS Reliability and Testing," mst-news, No. 3/07 - June 2007. (www.mstnews.de)

11. P. Azoley, J. Bon, and P. Pfluger, "MEMS: From the Foundry to the Products," mst-news, No. 3/07 - June 2007. (www.mstnews.de)

12. H. Petroski, Success through Failure: the paradox of design, (Princeton, N.J.: Princeton University Press, 2006)

13. "MIG Industry Report: Focus on Accelerated Lifetime Test,” MEMS Industry Group, January 2005.

14. R. Clandos, "Researchers Try to Toughen Up Tiny Machines So They Can Take the Heat, Stand Test of Time," Small Times, May 20, 2001.

15. B. Becker and R. Phillips, "Highly Accelerated Life Testing for the SXGA 1210 Digital Ruggedized Display," Texas Instruments Technical Journal, Vol. 15, No. 3, 1998, pp. 137-143.

16. R. Johnson, "M/A-COM qualifies MEMS oscillator for smart munitions," EE Times-Online, April 9, 2007.

17. R. Johnson, "MEMS launches software-defined radios in space," EETimes-Online, August 6, 2007.

18. See http://h30267.www3.hp.com/country/us/en/products/wide format/XL2200/faq.html\#benefits

19. R. Frank, "Packaging Edges into the Spotlight," Small Times, September/October, 2007. 